\title{
Comida na universidade: os efeitos da COVID-19
}

Food in university: the COVID-19 efects

Comida en la universidad: los efectos de COVID-19

Ludymila Schulz Barroso ${ }^{1}$, Angela Lautert Monteiro²

\section{RESUMO}

Em tempos de pandemia causada pelo coronavírus (SARS-CoV-2) e necessidade de distanciamento social, os Restaurantes Universitários precisaram adequar a forma de trabalho e de fornecimento de comida. Este ensaio aborda as alterações na produção e distribuição das refeições da Universidade Federal do Rio Grande do Sul (UFRGS) que, até meados de março de 2020, acontecia através do sistema de alimentação do tipo buffet livre para toda a comunidade acadêmica e, a partir da pandemia, foi alterado para a modalidade de refeições fracionadas em marmitas somente para para alunos em vulnerabilidade socioeconômica. Além disso, também investigou-se e discutiu-se sobre os impactos da pandemia na comida dos universitários em outras instituições de ensino público superior no Brasil. Observouse que as adequações adotadas perpassam pela Segurança Alimentar e Nutricional, soberania alimentar e comensalidade dos alunos, em meio a um contexto desconhecido e incerto, embora essencial. Por fim, apresentaram-se as novas medidas adotadas pela UFRGS, que visam diminuir os efeitos negativos da pandemia nos alunos em vulnerabilidade socioeconômica, bem como refletiu-se acerca das transformações na tradicional foram de comidas em buffet.

Palavras-chave: Comida; COVID-19; Pandemia; Restaurantes Universitários

\section{ABSTRACT}

In times of pandemic caused by the coronavirus (SARS-CoV-2) and the need for social distance, University Restaurants needed to adapt the way they work and provide food. This essay addresses changes in the production and distribution of meals at the Federal University of Rio Grande do Sul (UFRGS), which, until midMarch 2020, happened through the free buffet-style food system for the entire academic community and, from the pandemic, it was changed to fractionated meals

1 Divisão de Alimentação, Centro de Empreendimentos em Alimentação e Nutrição (CEANUT) da Universidade Federal do Rio Grande do Sul (UFRGS). Rio Grande do Sul, Brasil. E-mail: ludymila.barroso@gmail.com

2 Divisão de Alimentação, Universidade Federal do Rio Grande do Sul (UFRGS). Rio Grande do Sul, Brasil. E-mail: angelalautert@gmail.com 
in lunchboxes only for students in socioeconomic vulnerability. In addition, the pandemic impacts on university students' food in other public higher education institutions in Brazil were also investigated and discussed. It was observed that the adaptations adopted pervade Food and Nutrition Security, food sovereignty and students' commensality, in the midst of an unknown and uncertain context, although essential. Finally, the new measures adopted by UFRGS were presented, which aim to reduce the negative effects of the pandemic on students in socioeconomic vulnerability, as well as reflected on the transformations in the traditional buffet meals.

Keyworlds: Food; COVID-19; Pandemic; University Restaurants

\section{RESUMEM}

En tiempos de pandemia causada por el coronavirus (SARS-CoV-2) y la necesidad de distancia social, los restaurantes universitarios necesitaban adaptar su forma de trabajar y proporcionar alimentos. Este ensayo aborda los cambios en la producción y distribución de comidas en la Universidad Federal de Rio Grande do Sul (UFRGS), que, hasta mediados de marzo de 2020, se realizó a través del sistema de comida estilo buffet libre para toda la comunidad académica y, de la pandemia, se cambió a comidas fraccionadas en loncheras solo para estudiantes en vulnerabilidad socioeconómica. Además, los efectos de la pandemia en la comida de los estudiantes universitarios en otras instituciones públicas de educación superior en Brasil también fueron investigados y discutidos. Se observó que las adaptaciones adoptadas impregnan la Seguridad Alimentaria y Nutricional, la soberanía alimentaria y la semejanza estudiantil, en medio de un contexto desconocido e incierto, aunque esencial. Finalmente, se presentaron las nuevas medidas adoptadas por UFRGS, cuyo objetivo es reducir los efectos negativos de la pandemia en los estudiantes en la vulnerabilidad socioeconómica, así como reflexionar sobre las transformaciones en las comidas tradicionales de buffet.

Palabras Clave: Alimentos; COVID-19; Pandemia; Restaurantes universitarios

\section{Introdução}

A COVID-19, doença infecciosa causada pelo coronavírus (SARS-CoV-2), teve início em Wuhan, na China, em dezembro de 2019. Porém, na segunda quinzena de 2020, o Brasil recebeu as 10 primeiras notificações de casos para investigação de possível relação com a infecção humana por esse novo vírus, sendo que nenhuma das notificações resultou em caso confirmado(1). No entanto, com a rápida disseminação do SARS-CoV-2 para a maioria dos países e visando 
retardar a disseminação da doença, houve a necessidade de interromper as atividades diárias da população, dando início ao sistema de distanciamento social.

No estado do Rio Grande do Sul, no sul do Brasil, as medidas de prevenção à COVID-19 iniciaram em janeiro, poucos dias antes da Organização Mundial da Saúde declarar emergência em saúde pública, através da criação do Centro de Operações de Emergências e do lançamento do Plano de Ação e Contingência para se preparar para o monitoramento, controle e assistência a possíveis casos no estado. Porém, em 19 de março de 2020, o estado decretou situação de calamidade pública em todo o território do Rio Grande do Sul, com restrições mais rígidas para evitar a propagação do vírus ${ }^{(2,3)}$.

Nesse contexto, a Universidade Federal do Rio Grande do Sul (UFRGS) suspendeu as atividades presenciais na universidade ${ }^{(4)}$, possibilitou aos servidores aexecução das suas atribuições em regime excepcional de trabalho remoto, instituiu o revezamento de jornada de trabalho para aqueles servidores a quem não é possível a aplicação do trabalho remoto, garantindo o desenvolvimento das atividades e infraestruturas essenciais ${ }^{(5)}$. Contudo, diante de todas essas alterações, outro lado emergente da pandemia envolve a Segurança Alimentar e Nutricional (SAN) dos alunos da Universidade, mais especificamente dos alunos em vulnerabilidade socioeconômica, uma vez que os Restaurantes Universitários (RUs) também tiveram seu funcionamento tradicional cessado.

O conceito de SAN é relativamente novo, uma vez que este termo só passou a fazer parte das discussões de políticas públicas brasileiras em 1985, como uma proposta de combate à fome, tendendo à autossuficiência e acesso universal(6) Somente duas décadas mais tarde, em 2006, foi criado o Sistema Nacional de

Segurança Alimentar e Nutricional, com vistas a assegurar o Direito Humano à Alimentação Adequada, qual seja um direito fundamental do ser humano, devendo o poder público adotar políticas e ações necessárias para promover e garantir a SAN, cujo objetivo consiste:

[...] na realização do direito de todos ao acesso regular e permanente a alimentos de qualidade, em quantidade suficiente, sem comprometer 0 
acesso a outras necessidades essenciais, tendo como base práticas alimentares promotoras de saúde que respeitem a diversidade cultural e que sejam ambiental, cultural, econômica e socialmente sustentáveis. ${ }^{(7)}$

Para além da SAN, não há outra política pública de alimentação que vise especificamente o grupo populacional de adultos jovens em fase universitária, a exemplo do Programa Nacional de Alimentação Escolar, com foco em crianças e adolescentes. Havendo, apenas, a Política Nacional de Assistência Estudantil (PNAES), cuja finalidade é a permanência de estudantes em situação de vulnerabilidade social e econômica na universidade até a conclusão da graduação de ensino superior. A partir do PNAES, há a disponibilização de recursos financeiros para subsidiar moradia estudantil, alimentação, transporte, saúde, cultura, entre outros, os quais devem ser monitorados e administrados pelas próprias universidades ${ }^{(8)}$.

Nessa temática, Xafis ${ }^{(9)}$ explora maneiras pelas quais certos grupos que já sofrem desvantagens econômicas ou sociais estão sendo afetados pela COVID-19. Entre outras análises feitas por esse autor, o acesso à educação figurou como papel importante, mostrando que a incapacidade de acesso à educação, geralmente, afeta a saúde e a vida de maneira mais ampla, direta e indiretamente, em vário estágios da vida da pessoa, demonstrando que a interrupção das atividades acadêmicas, bem como da alimentação proporcionada pelos RUs podem ser mais um fator influenciador no desenvolvimento da COVID-19.

Diante disso, nota-se a importância do PNAES como um pilar de apoio na permanência dos estudantes na universidade. E, portanto, a UFRGS disponibiliza, por exemplo, moradias estudantis no entorno de seus campi e auxílios saúde e material escolar para alunos vulneráveis socioeconomicamente, além de RUs para toda a comunidade acadêmica ${ }^{3}$ É importante salientar que a baixa renda e a dificuldade de acesso à alimentação fora dos RUs são situações enfrentadas, principalmente, pelos alunos residentes das moradias estudantis. Muitos

\footnotetext{
3 A comunidade acadêmica da Universidade Federal do Rio Grande do Sul é composta por alunos de graduação e pós-graduação, prestadores de serviço terceirizados, servidores docentes e servidores técnico-administrativos.
} 
moradores, por exemplo, se alimentam, ao longo do dia, somente com o que é oferecido pela Universidade.

Os RUs representam o grupo de restaurantes institucionais que oferecem, diariamente, um número expressivo de refeições à comunidade acadêmica, podendo ser considerados um dos principais equipamentos públicos para promoção de SAN no país, por meio da oferta de refeições saudáveis aos estudantes universitários $^{(10)}$. Durante o período letivo, na UFRGS, o número de refeições entre os sete RUs totaliza cerca de 11 mil refeições ao dia. Todavia, o serviço que, até meados de março de 2020, era ofertado para toda a comunidade acadêmica, através do sistema de alimentação do tipo buffet livre, ou seja, o comensal serve-se ad libitum, com exceção da proteína animal e da sobremesa, as quais são limitadas a uma porção por pessoa por refeição (almoço e/ou jantar), foi alterado para a modalidade de refeições já fracionadas em marmitas e somente para beneficiários das ações de assistência estudantil da Pró-Reitoria de Assuntos Estudantis (PRAE), ou seja, para os alunos em vulnerabilidade socioeconômica(11).

Observa-se, portanto, que o ato de comer e os fatores que envolvem a função social das refeições e a comensalidade, foram alterados não pelo que se come, mas como se come. Da Matta(12) já dizia que: "comida não é apenas uma substância alimentar, mas é também um modo, um estilo e um jeito de alimentarse. E o jeito de comer define não só aquilo que é ingerido como também aquele que ingere".

A pesquisa elaborada por Berbigier ${ }^{(13)}$ corrobora com esta colocação ao mostrar que os alunos vêem a alimentação ofertada pelos RUs como comida, uma vez que as entrevistas feitas pela autora trazem relatos de que a comida é bem feita, sem bactéria, bem preparada, bem cozida e no tempo certo.

Diante do exposto, partindo da experiência prática na UFRGS, o objetivo desse ensaio é discutir sobre as modificações pelas quais os RUs das universidades e institutos federais brasileiros tiveram que passar e refletir como será o futuro da alimentação nas universidades. 


\section{O que alimentação tem a ver com comida?}

Em ambientes institucionais, os quais possuem o objetivo de ofertar alimentação adequada e saudável com qualidade sanitária e sensorial aos seus comensais, o sentido cultural e afetivo da alimentação, por vezes, pode ser perdido. Isto porque o termo "alimentação", geralmente, recebe um tratamento mais formal, relacionando-se a uma questão vital, uma necessidade comum e de direito a todos os seres humanos ${ }^{(14,15)}$. No Brasil, isso está assegurado entre os direitos sociais da Constituição Federal desde 2010. Em atendimento à legislação vigente, os conceitos-chave para realização do Direito Humano à Alimentação Adequada, tais como disponibilidade, adequação e acesso (físico e econômico) de alimentos são garantidos pelos RUs da UFRGS.

Por outro lado, o termo "comida" abarca todo um viés cultural e social, pois representa as vivências alimentares do dia a dia e não somente de épocas festivas ou momentos comemorativos ${ }^{(14)}$. Farias de Lima e Montanari(15) corroboram ao afirmarem que a comida é cultura, seja por criarmos nosso próprio alimento ao cozinhá-lo ou selecionarmos o que comer com base em diversos critérios (econômicos, religiosos, nutricionais, etc.).

Assim sendo, identifica-se que a alimentação também está envolvida com a cultura de seu comensal, bem como da cidade, estado e país onde o comensal está localizado. Nesse sentido, não só os ingredientes, mas todo o processo de preparo e modo de servir também são importantes e estão ligados à comensalidade dos indivíduos e suas escolhas alimentares. Um perfeito exemplo disto é o feijão, ingrediente indispensável na culinária brasileira. Em alguns lugares, ele é cozido só com temperos e, em outros, recebe temperos e farinha de mandioca, o que deixa a preparação totalmente diferente tanto na textura, quanto no sabor. Além disso, a variedade do feijão também difere conforme a região do Brasil: por exemplo, no sul, se consome muito mais feijão preto e no nordeste, feijão carioca. Esses pontos manifestam a identidade alimentar de um grupo social e expressam sua cultura, sendo claramente percebido nos RUs, uma vez que as instituições de ensino 
público superior recebem alunos do país inteiro. Já dizia Garine(16), "o homem se alimenta de acordo com a sociedade a que pertence".

A comensalidade nos RUs contempla perfeitamente esses dois conceitos, uma vez que devem ofertar uma alimentação adequada, segura e saudável, nos termos preconizados pelos órgãos de saúde, mas também representam a comida diária de um grande número de pessoas, em sua maioria adultos jovens, estudantes de cursos de graduação e pós-graduação com suas diversas preferências alimentares arraigadas em suas culturas. Outrossim, Amon e Menasche(14) apresentaram a ideia de que a comida é um modo de comunicação de uma sociedade e pode contar histórias, a partir da associação entre comida, cultura e memória. Segundo eles, "a comida constituiria, assim, um veículo para manifestar significados, emoções, visões de mundo e identidades, bem como um modo de transformar, pela resolução de conflitos, e realizar mudanças e desistências.".

Nos RUs da UFRGS, essa comunicação gerada pela comida pode ser identificada na rotina dos comensais, que vai desde verificar o cardápio do dia até efetivamente comer. Por exemplo, os comensais combinam o almoço/jantar com seus colegas de aula ou trabalho e isso gera um engajamento, que pode ser visualizado nas filas e nas mesas dos restaurantes, quando grupos de amigos interagem e usam esse momento, não só para se alimentar, mas também para descontrair. Além disso, outras ações fazem parte desse processo de comunicação, afetando a comensalidade de cada um: no descarte das eventuais sobras de comida nos pratos, quando alguém observa que um comensal não as descarta no local correto, outro colega chama sua atenção e o corrige; e, na copa, quando o funcionário está atento para a quantidade de pratos disponíveis e daqueles que precisam ser limpos e repostos para os alunos que estão acessando os RUs.

Ainda no contexto da comida como instrumento de comunicação e, buscando ampliar o foco, antes centrado nos ingredientes, na coleção de receitas culinárias e no valor nutricional dos alimentos, para uma perspectiva que inclui as dimensões psicológica e social, englobando atitudes, hábitos, sistemas de refeições 
e cultura material relacionados à comida, a Universidade criou o blog "Laranja na Colher", cujo nome ilustra perfeitamente um comunicado da comida nos RUs. Os comensais mais antigos relatam que as facas, praticamente sem fio, eram inúteis para a missão de descascar uma laranja e foram substituídos pelas colheres, de tal modo que a faca desenha uma circunferência em volta da laranja e a colher inicia seu movimento entre a casca e o fruto, como uma pá, até restar uma esfera rodeada por uma película branca, pronta para ser saboreada(17).

Essa mensagem é, então, introduzida aos calouros que chegam aos RUs, tanto por seus veteranos, quanto pela equipe técnica de nutrição que alimenta e gerencia o blog, no intuito de estreitar os laços entre os alimentos e a comida dos RUs com a comunidade acadêmica(17). No entanto, neste período de pandemia, essa interação e imersão no cotidiano do comensal e do restaurante, em certa medida, foi perdida e interfere na elaboração dos cardápios, no conhecimento sobre a quantidade de sobras e se a comida está, de fato, agradando e cumprindo o seu papel de alimentar e também de trazer prazer durante a refeição. Isto porque a comida ofertada aos alunos está disposta em marmitas já fracionadas e prontas, entregues individualmente para que os alunos peguem e levem para consumir em seus quartos nas moradias estudantis.

\section{A comida dos universitários na era pré COVID-19}

A Universidade Federal do Rio Grande do Sul possui cinco campi espalhados pela cidade de Porto Alegre/RS e um campus no litoral norte do estado, necessitando, assim, de restaurantes universitários em número suficiente para alimentar essa ampla comunidade acadêmica, uma vez que, em muitas vezes, estes são responsáveis diretos pela redução dos índices de evasão escolar(18).

Desse modo, a UFRGS conta com sete RUs, ou seja, pelo menos, um restaurante por campus, principalmente, porque muitos alunos em vulnerabilidade socioeconômica não teriam condições financeiras de realizar suas refeições em cantinas ou restaurantes privados, dado que as refeições nos RUs são subsidiadas 
e os alunos pagam um valor simbólico, enquanto que os estabelecimentos particulares não recebem subsídios ${ }^{(18)}$.

A maioria dos institutos e universidades federais brasileiras oferecem as três principais refeições em seus RUs: café da manhã, almoço e jantar, sendo que o café da manhã, geralmente, é exclusivo aos alunos que residem nas moradias estudantis destas instituições. Na UFRGS, os cardápios são elaborados em acordo com as orientações preconizadas pelo Guia Alimentar para a População Brasileira $^{(19)}$, por profissionais nutricionistas habilitados. Antes da pandemia da COVID-19 se instalar no país e no estado, as refeições eram distribuídas em equipamentos de buffet para que os próprios comensais pudessem visualizá-las, escolhê-las e servi-las em seus pratos.

No café da manhã, os alunos moradores das três casas de estudantes da UFRGS podiam escolher, diariamente, entre pão branco (apresentado como pão francês, pão tipo massinha e pão fatiado, a depender do dia da semana) ou integral; e, café passado, leite frio ou quente. Além disso, a cada dia, uma diferente fruta e variados acompanhamentos estavam disponíveis, tais como: bolo, doce de fruta, iogurte, margarina, molho de tomate, ovos mexidos, presunto, queijo e suco natural de fruta. Enquanto isso, o almoço e o jantar eram disponibilizados para toda a comunidade acadêmica e não somente aos alunos das moradias estudantis. Em um mesmo dia, o cardápio de almoço e jantar eram iguais, mas eram diversificados diariamente ao longo dos meses. Estas refeições tinham como padrão a oferta de 2 tipos de salada, 1 opção de molho para a salada (além de vinagre), arroz branco e integral, 1 variedade de leguminosa, 1 tipo de acompanhamento, 1 opção de proteína animal e vegetal e 1 sobremesa, que, majoritariamente, era fruta in natura.

O aluno estar presencialmente diante de todas estas preparações permitia que ele exercesse a comensalidade baseada em suas próprias crenças, culturas e desejos. Era possível que o comensal escolhesse qual destas opções queria comer e a quantidade de cada uma delas, assim como a possibilidade de diversificar o tipo de proteína, por exemplo, entre as refeições de almoço e jantar e a oportunidade de 
se servir novamente (com exceção da opção proteica), caso tivesse ficado com fome ou a preparação estivesse apetitosa para ele.

Nota-se, portanto, que a comensalidade nos RUs pode emitir comunicados, mesmo sem a necessidade de efetivamente falar frase alguma para os funcionários. Esse processo envolve diversas etapas: a espera na fila externa; o registro da refeição com as atendentes dos caixas, as quais cumprimentam os alunos, já conhecendo as peculiaridades de alguns; a higienização das mãos; a pega dos talheres e prato, que, muitas vezes, passa pela escolha das facas com melhor fio; a fila interna para chegar ao equipamento de buffet; o auto-servimento das preparações, onde os comensais podem escolher o tipo de arroz e as demais opções, bem como a quantidade desejada; o servimento da opção proteica (animal ou vegetal) e sobremesa, as quais são fracionadas e servidas por uma atendente, uma vez que a Universidade contrata refeições com estas porções padrão para cada comensal; a escolha de uma mesa disponível para comer; o comer, seja ele sozinho ou com seus amigos; o descarte de possíveis sobras de comida nos pratos, o que pode indicar, por exemplo, que a comida não estava saborosa; a entrega dos talheres e pratos sujos para os copeiros higienizarem; e, por fim, a saída do restaurante, geralmente, com um cumprimento final para o vigilante que observa o transcorrer das atividades dos RUs diariamente.

Nesse sentido, Fernandes, de Barros e de Oliveira(20) ${ }^{(20 n c o r d a m ~ q u e ~ e s s a ~}$ comensalidade presencial nos RUs, juntamente com a observação de cada etapa acima mencionada, pode entregar algumas mensagens e sugestões aos profissionais que prepararam as refeições ou aos gestores. No RU estudado por eles, identificou-se que almôndega e carne moída são "carnes que os estudantes não gostam, acaba sobrando muito", enquanto no dia em que é servido peixe há mais movimento, "porque eles gostam mais". Estes autores acreditam que esse conhecimento do gosto dos comensais se viabilizou, dentre outras razões, pela imersão dos profissionais no cotidiano do RU.

É sabido, entretanto, que a pandemia da COVID-19 afetou diretamente todas as atividades que requerem muitas pessoas, sejam elas profissionais ou clientes. 
Assim, as atividades acadêmicas presenciais foram suspensas e os RUs da UFRGS também tiveram de interromper seu funcionamento tradicional, transpondo um novo modo de comer, uma nova comensalidade aos alunos da Universidade. Mas, como ilustrado por Fernandes, de Barros e de Oliveira(20) não só os alunos foram afetados, por isso. Os próprios cozinheiros e demais profissionais envolvidos com a produção das refeições perderam os comunicados, as mensagens e os sinais que a comida lhes dava.

\section{A comida em tempos de COVID-19 nas universidades brasileiras}

Com o início da pandemia da COVID-19, a UFRGS buscou maneiras de manter uma alimentação adequada e saudável aos alunos em vulnerabilidade socioeconômica que não tiveram a possibilidade de retornar aos seus lares de origem, pois, assim como outras necessidades básicas, a comida também é fundamental para todos nós.

Diante disso, pensando nos meios de evitar contatos interpessoais e possíveis contágios, a Universidade entendeu que distribuir a comida em marmitas seria a opção mais adequada, uma vez que simplesmente disponibilizar auxílio financeiro para que os próprios alunos adquirissem seus alimentos poderia ir contra ao princípio da alimentação adequada e saudável, bem como às medidas de contingenciamento ao coronavírus, visto que estes alunos necessitam utilizar as mesmas cozinhas nas moradias estudantis, as quais não comportam o distanciamento mínimo recomendado.

Essa ação corrobora com atitudes adotadas em outros países como Itália, Espanha e Portugal, já em distanciamento social, os quais desenvolveram iniciativas para evitar aglomerações que impactaram na cadeia alimentar. Nesses países, a maioria dos restaurantes e bares foi fechada e os supermercados adotaram regras para acesso e compra de produtos alimentícios, a fim de evitar a escassez $^{(21)}$. 
Mesmo diante desse novo sistema de oferta de alimentação, a Universidade procurou manter a soberania dos alunos na escolha da sua comida, dentro das possibilidades administrativas da produção destas refeições. Para isso, foi disponibilizado um formulário eletrônico, para que os alunos selecionassem como desejavam receber as refeições de almoço e jantar, podendo optar entre arroz branco ou integral e proteína animal ou vegetal. Assim, respeitou-se parte das preferências alimentares de cada um, de modo que eles pudessem exercer suas crenças e culturas, tornando estas refeições em suas comidas. Entretanto, o restante das preparações se remete a um cardápio similar ao período pré COVID19: 2 saladas, 1 leguminosa, 1 acompanhamento e 1 sobremesa, com a diferença de que, agora, o aluno não pode escolher sobre a presença ou ausência destas preparações em sua marmita.

Assim sendo, as questões que interferem, em partes, na soberania alimentar dos alunos são: (I) a quantidade de cada uma destas preparações, porque todas as marmitas são compostas por porções padrão de cada preparação, baseadas na média de consumo, quando em funcionamento presencial dos RUs; (II) o consumo de molho para salada ou vinagre, pois a comida em marmitas não contém estes complementos; e, (III) a preferência alimentar como, por exemplo, comer ou não as leguminosas ou certos tipos de legumes, uma vez que todas as marmitas são compostas por todas essas preparações. Cabe salientar que essa autonomia não foi totalmente perdida, considerando que, em alguns casos, ainda há a alternativa do aluno não comer o alimento que ele desgosta ou adquirir individualmente o vinagre, por exemplo.

Em relação ao café da manhã, a Universidade utilizou os mesmos percentuais a respeito das proteínas animal e vegetal das grandes refeições, a partir do resultado da consulta aos alunos, para definir a comida ofertada, atendendo, mais uma vez, as especificidades alimentares de cada aluno. Neste momento, surgiram as maiores dificuldades e exigências de mudanças, pois, em marmitas, os pães já são distribuídos com recheio, o que deixava os alunos adeptos ao vegetarianismo e veganismo desassistidos. Isto porque quando, no 
cardápio, a comida continha alimentos de origem animal, esses alunos recebiam apenas margarina em substituição, diante da ausência de outras alternativas. Foi, então, que novas preparações foram criadas para garantir uma comida saborosa e uma alimentação adequada e saudável. Dentre elas, destacam-se duas pastas: de abacate e de grão de bico. Após essas adaptações, as reclamações dos alunos nesse sentido cessaram, o que pode ser um indicativo de que suas necessidades alimentares foram atendidas.

Por outro lado, este sistema de comida em marmitas interfere também no trabalho dos profissionais envolvidos na produção das refeições, os quais perdem acomunicação e os sinais que a comida emite direta e constantemente no sistema de alimentação presencial nos RUs. Estes profissionais perderam a referência sobre a qualidade do seu trabalho, pois não conseguem observar a demanda de consumo que determinada preparação teve e o comportamento dos alunos no tange as sobras de comida em seus pratos. Embora, cozinhar seja um trabalho que, muitas vezes, transcorra desapercebidamente, o resultado pode ser visto claramente no apetite dos comensais, de modo a comida que acaba rapidamente é reconhecida como comida boa ${ }^{(20)}$.

Ainda assim, é importante destacar que os alunos mantêm um canal de comunicação com a Universidade, trazendo à tona diversos apontamentos sobre esta comida, os quais são repassados aos profissionais que a produzem. Contudo, não há nada mais eficaz que o dia a dia de interação e movimentação com os comensais para efetivamente captar sua satisfação perante à comida, uma vez que as manifestações atuais, geralmente, ocorrem quando há pontos negativos a serem colocados. Enquanto que os pontos positivos são recebidos em menor proporção que os negativos, ou até mesmo que a ausência de manifestações.

No intuito de conhecer como as demais instituições de ensino público superior do Brasil tiveram seu sistema de alimentação impactado, procedeu-se uma breve consulta eletrônica, obtendo-se, assim, 21 respostas. Destas, até o momento, somente 1 universidade está trabalhando do mesmo modo que a UFRGS, por meio da oferta de comida em marmitas, tanto para os alunos e profissionais que estão 
trabalhando em ações de enfrentamento à COVID-19, quanto para os alunos moradores de sua respectiva moradia estudantil. Até o mês de abril deste ano, outras 3 universidades também disponibilizaram marmitas ou gêneros alimentícios in natura para os alunos em vulnerabilidade socioeconômica, no entanto, atualmente, todas elas estão com seus RUs fechados.

Ao total, 18 universidades estão fornecendo alimentação através do repasse de auxílio financeiro para os alunos em vulnerabilidade socioeconômica registrados em suas universidades, sejam eles residentes ou não das moradias estudantis. Questiona-se, entretanto, a efetividade dessa transformação da comida dos RUs em recurso financeiro, considerando que muitos alunos não possuem habilidades culinárias, conforme demonstram alguns estudos(22-24). Nota-se que mesmo estudantes em nutrição possuem insegurança acerca de certas práticas básicas no preparo de alimentos, cuja familiaridade com alimentos é, geralmente, maior do que de estudantes de outras áreas do conhecimento(22-24). Pondera-se, portanto, quais as características da comida que estes alunos irão comer a partir do auxílio financeiro disponibilizado: uma alimentação adequada e saudável ou uma alimentação pré-pronta, industrializada e não saudável? Este é um grande paradigma que a pandemia da COVID-19 trouxe para as instituições de ensino superior em relação à comida de seus alunos, especialmente, àqueles em vulnerabilidade socioeconômica: como executar medidas de contenção ao coronavírus e garantir comida de qualidade?

Um estudo realizado em 2007, em uma universidade pública, demonstra a importância da comida ofertada pelos RUs, ao identificar que a maioria dos entrevistados realizava a refeição de almoço no $\mathrm{RU}$ e a considerava completa. Enquanto que o jantar foi realizado no RU por um menor número de estudantes e, assim, foi considerado incompleto por mais da metade dos entrevistados. Além disso, estes mesmos autores defendem que é necessário incentivar que o restaurante universitário, acessível aos estudantes, seja uma maneira de garantir uma refeição adequada, visto que eles já possuem uma representação simbólica positiva neste aspecto $^{(25)}$. 
Por fim, é sabido que a pandemia da COVID-19 afetou diretamente a comensalidade destes alunos também ao limitar a partilha do comer com amigos. Entende-se que esta é uma situação complexa de solucionar, no momento, mas é mais uma representação das diversas possibilidades culturais da alimentação que os RUs trazem para os alunos. Um entrevistado do estudo de Alves e Boog(25) disse: "o sentido afetivo altera muito a alimentação, não é a mesma coisa comer com alguém que você gosta ou com uma pessoa qualquer, como não é a mesma coisa comer em casa com a família e comer no bandejão [restaurante universitário]."

\section{Considerações finais}

Entende-se que o comer sofreu inúmeros impactos com a pandemia da COVID-19 e assegurar uma alimentação adequada e saudável, bem como uma comida afetiva e saborosa é algo fundamental. Acredita-se que gerenciar todas estas transformações é um caminho necessário, embora desconhecido e incerto, principalmente porque ainda não há previsões assertivas sobre o retorno da rotina da UFRGS, e também das demais instituições de ensino público superior, para uma realidade próxima do que era antes da chegada do coronavírus ao sul do Brasil.

Recentemente, a UFRGS anunciou um plano de ensino remoto emergencial, o que levou à elaboração de novas medidas que visam diminuir os efeitos negativos causados pela pandemia aos alunos em vulnerabilidade socioeconômica. Dentre estas iniciativas, a continuidade da oferta de comida em marmitas está garantida, mas um auxílio financeiro para aquisição de alimentos também será implementado, entretanto este não atuará como um substituto à disponibilização de comida em marmitas, em virtude das razões já arroladas neste ensaio. Este último visa oportunizar que os alunos, que puderam regressar aos seus lares de origem, comprem seus próprios alimentos. E assim, considerando a probabilidade de estarem com seus familiares, a possibilidade de eles fazerem comidas caseiras e saudáveis com este recurso é maior do que os alunos que seguem nas Casas de 
Estudantes da Universidade, os quais também receberão auxílios para complementarem sua alimentação.

Em relação às adaptações que a pandemia tem trazido às nossas comidas, especialmente no que tange 0 uso de marmitas, precisa-se considerar a insustentabilidade que estas embalagens trazem para o processo, assim como a soberania de cada aluno em termos de preferências alimentares e quantidade de alimentos. Mas, para além disso, quais serão os impactos que deixarão marcas duradouras em nossos tradicionais modos de se alimentar nas instituições de ensino público superior? Atualmente, o funcionamento de restaurantes no estilo buffet está proibido em muitos estados do Brasil, sejam eles comerciais ou institucionais. Já existem algumas alternativas sendo aplicadas como, por exemplo, um profissional servir cada comensal, a fim de evitar o contato de inúmeras pessoas no mesmo talher de servir. Entretanto, será que na era pós COVID-19 haverá se solidificado uma grande transformação no sistema de alimentação dos RUs? O quanto isso afetará a comida e a comensalidade de cada aluno?

\section{Referências}

1. Brasil. Ministério da Saúde. Boletins Epidemiológicos. Disponível em: https://coronavirus.saude.gov.br/boletins-epidemiologicos [Acesso em 5 jun de 2020].

2. Organização Pan-Americana de Saúde - OPAS. Folha informativa - COVID-19 Escritório da OPAS e da OMS no Brasil. Disponível em:

https://www.paho.org/bra/index.php?option=com_content\&view=article\&id=6101: covid1 9\&Itemid=875 [Acesso em 5 jun 2020].

3. Portal do Estado do Rio Grande do Sul. Histórico. Disponível em: https://estado.rs.gov.br/historico [Acesso em 3 jun 2020].

4. Universidade Federal do Rio Grande do Sul. Legislação. Portaria 2286, de 17 de março de 2020 - UFRGS: suspende atividades presenciais de ensino na Universidade. Disponível em: https://www.ufrgs.br/ensinoremoto/legislacao/ [Acesso em 3 jun 2020].

5. Universidade Federal do Rio Grande do Sul (UFRGS). Reitoria institui portarias que regulam atividades durante período de suspensão de aulas (Portaria $\mathrm{n}^{\circ}$. 2.291 de 17/03/2020, trata da suspensão das atividades presenciais de ensino na UFRGS e da utilização das modalidades a distância). Disponível em: 
http://www.ufrgs.br/ufrgs/noticias/reitoria-institui-portarias-que-regulamatividades-durante-periodo-de-suspensao-de-aulas [Acesso em 3 jun 2020].

6. Belik W. A política brasileira de segurança alimentar e nutricional: concepção e resultados. Segurança Alimentar e Nutricional, 2012;19(2):94-110.

7. Brasil. Lei №. 11.346, de 15 de setembro de 2006. Cria o Sistema Nacional de Segurança Alimentar e Nutricional - SISAN com vistas em assegurar o direito humano à alimentação adequada e dá outras providências. Disponível em: http://www.planalto.gov.br/ccivil_03/_Ato2004-2006/2006/Lei/L11346.htm [Acesso em 3 jun 2020]

8. Brasil. Ministério da Educação. Portaria Normativa n‥ 39 de 12 de dezembro de 2007. Institui o Programa Nacional de Assistência Estudantil - PNAES.

Disponível em: http://portal.mec.gov.br/arquivos/pdf/portaria_pnaes.pdf [Acesso em 3 jun 2020].

9. Xafis $V$. 'What is Inconvenient for You is Life-saving for Me': How Health Inequities are playing out during the COVID-19 Pandemic. Asian Bioethics Review volume 12, pages223-234(2020). Disponível em: http://link.springer.com/10.1007/s41649-020-00119-1 [Acesso em 29 mai 2020]

10. Barroso LS. As compras institucionais da Universidade Federal do Rio Grande do Sul : dietas sustentáveis em restaurantes universitários. Dissertação. Porto Alegre: Universidade Federal do Rio Grande do Sul, 2019. Disponível em: https://lume.ufrgs.br/handle/10183/197218 [Acesso em 29 de maio de 2020].

11. Universidade Federal do Rio Grande do Sul - UFGRS. Pró-Reitoria de Assuntos Estudantis - PRAE. Alterações nos serviços PRAE durante periodo de contenção COVID-19. Disponível em: https://www.ufrgs.br/prae/alteracao-nosservicos-prae-durante-periodo-de-contencao-do-covid-19/ [Acesso em 3 jun 2020].

12. Matta R. Sobre o simbolismo da comida no Brasil. O Correio da Unesco. 1987;15(7):22-3.

13. Berbigier MC. Estado nutricional e elementos para promoção de saúde alimentar em restaurantes universitários. Dissertação. Porto Alegre: Universidade Federal de Ciências da Saúde de Porto Alegre - UFCSPA; 2017.

14. Amon D, Menasche R. Comida como narrativa da memória social. Sociedade $E$ Cultura. 11(1). Disponível em:

http://www.revistas.ufg.br/index.php/fchf/article/view/4467 [Acesso em 3 jul 2020]

15. Lima MFF. Comida como cultura. Revista de Ciências Sociais. 2009;40(1):107111.Disponível em: http://www.periodicos.ufc.br/revcienso/issue/view/69 [Acesso em 3 jul 2020]

16. Garine I. Alimentação, culturas e sociedades. $O$ Correio da Unesco. 1987;15(7):4-7. 
17. Universidade Federal do Rio Grande do Sul - UFGRS. Laranja na Colher. Disponível em: https://www.ufrgs.br/laranjanacolher/ [Acesso em 3 jul 2020]

18. Moreira Junior FDJ net al. Satisfação dos usuários do restaurante universitário da Universidade Federal de Santa Maria: uma análise descritiva. Revista Sociais E Humanas. 2016;28(2):83-108.

19. Brasil. Ministério da Saúde. Guia alimentar para a população brasileira. Brasília: Ministério da Saúde, 2014. Disponível em:

https://bvsms.saude.gov.br/bvs/publicacoes/guia_alimentar_populacao_brasileira _2ed.pdf [Acesso em 3 jul 2020].

20. Fernandes CP, Barros MEB, Oliveira SP. Histórias do trabalho em um Restaurante Universitário: entre conversas, panelas e temperos. Mnemosine. 2012;8(1):90-116.

21. Oliveira TC, Abranches MV, Lana RM. (In)Segurança alimentar no contexto da pandemia por SARS-CoV-2. Cad Saúde Pública. 2020;36(4):e00055220.

22. Jomori MM, Vasconcelos F de AG de, Bernardo GL, Uggioni PL, Proença RP da C. The concept of cooking skills: A review with contributions to the scientific debate. Rev Nutr. fevereiro de 2018;31(1):119-35.

23. Lopes DL. Avaliação das habilidades culinárias e alimentação saudável de estudantes de nutrição da Universidade Federal do Rio Grande do Sul. Trabalho de Conclusão de Curs. Porto Alegre: Universidade Federal do Rio Grande do Sul; 2019. Disponível em: http://hdl.handle.net/10183/204326 [Acesso em 3 jul 2020]

24. Rosa M, Moura FA. Avaliação das habilidades culinárias de estudantes de nutrição. Anais do Salão Internacional de Ensino, Pesquisa e Extensão. 11(1). Disponível em:

https://periodicos.unipampa.edu.br/index.php/SIEPE/article/view/87668 [Acesso 3 jul 2020]

25. Alves HJ, Boog MCF. Comportamento alimentar em moradia estudantil: um espaço para promoção da saúde. Rev Saúde Pública. 2007;41(2):197-204. 